\title{
INFLUENCE OF NURSERY EDUCATION ON COGNITIVE COMPETENCE AMONG PUPILS IN PUBLIC PRIMARY SCHOOLS IN SOKOTO STATE. DOES IT PERSIST OR FADE?
}

\section{Dr. (Mrs.) A. A. BAGUDO}

\begin{abstract}
This study used survey research to examine the relationship in performances of pupils with nursery education in cognitive competence across the first three years of primary school in Sokoto State. The aim was to find out if the academic gains of nursery education are sustained or diminished through the first three years in primary school. Stratified random sample was used to choose 300 boys and 300 girls. Self designed, validated and reliable instrument on cognitive competence was used. One nullhypothesis was generated and tested using regression statistics. The hypothesis was rejected because the study found significant coherence in cognitive competence of pupils across the first three years in primary school. The study recommends stakeholders to provide complementary quality education and linkage between nursery and primary education, and to ensure that psycho-social and character assessments are conducted and included in result reports and certificates as evidences of learning outcomes attained by learners.
\end{abstract}

\section{Background to the Study}

There are series of theoretical opinions, framework and practices as well as advocates that served as practical foundation for nursery education, such as Fredric Wilhelm Froebel 1782-1852 and Maria Montessori 1870-1952 (in Essa 1999). Currently quality care and education for young children are seen as an important recipe not only for development of human capacities and enhancing their competencies in many domains, including cognition, language, literacy, mathematics, social-emotional, psychological and physical development, but also for continuous lifelong education that begins from birth. The preschool activities and programmes are guided by conceptual and curricula framework or established practices designed as early care, development, stimulation, intervention, education and training programmes meant to enhance participation, continuous success and completion of educational pursuits (EFA, MDG programmes).

Robust literature is available on various dimension of early years care and learning provisions. However, findings are still not conclusive as they vary on its benefits and lasting effects indicting either positive ( EFA,2000; EPPE 2000), negative (Orange 2009), short-term (Snell 2009 and Kare 2009), long term (Zaveri 1993), fade out (Barnett 1993; Lee and Loeb 2009), marginalisation (Sammon, Sylva, Melhuish, Saraj, Taggart, and Hunt, 2008; Morcan 1999; Keytaz 2004 and Berlinski 2008), slowed down (Barnett, 1995; 2007), effects on the cognitive, psycho-social and other domains of achievements of nursery school participants as they proceed schooling. 


\section{Statement of the Problem}

The assumption is that nursery education is key predictor for success in school or academic success as it eases transition to primary school and the gains are retained such that those with nursery education (ECCDE) are considered to be at advantage over those without in schooling career. This assumption needs to be justified by empirical research, more so as it applies to the practice of public nursery education (ECCDE) in Sokoto State. Some people believe that the influence of nursery education is short-term, meaning to say it does fade or become marginalised after some years of formal primary school instructions, such that the difference between those who attended nursery education and those who do not tend to diminish. But others believe that the influences are long term that extend to primary school and through higher learning. On the basis of this argument, this study used class three children of primary schools to find out whether the influence of exposure to nursery school education persists, diminishes or marginalised.

\section{Objective}

To find out the relationship between cognitive achievement results in Primary one and two and cognitive competence results in class three.

\section{Research Question}

Is there any significant relationship between primary one and two cognitive achievement results and cognitive competence of primary school pupils in Sokoto state?

\section{Hypothesis}

There is no significant relationship between primary one and two cognitive achievement results and cognitive competence result of primary three pupils in Sokoto state.

\section{Significance of t te Study}

This study was a le to establish the continuing influence of nursery education on performances of primary school children. The result of the study has helped to substantiate the assumptions that the benefits of nursery education can last up to class three level in primary school. However, issue of fading or marginalization has not been substantiated by current findings. This has some implication for further research. Findings and recommendations offered could help to promote ECCDE as component of UBE scheme. The findings support the use of quality driven ECCDE to promote access, and equal opportunities among learners and also enhance sustainable longterm benefits and linkages between preschool and primary school education to facilitate continuing and lifelong education. 


\section{Literature Review}

\section{Conceptual Framework}

Nursery School Education refers to pre-primary school programme for children between the ages of 3-5 years, which is currently provided in primary schools under the auspices of ECCDE. Cognitive competence simply refers to the level of efficiency that a child has attained under the condition of learning and training in nursery and primary education. It is the disposition for performing school work as measured by performance in cognitive competence questionnaire designed for this study. Cognitive achievement refers to end of term or end of year examination results when the primary pupils three used in this study were in primary one and two.

Fundamentally, nursery education (ECCED) is based on the belief that children are born as unique entity with potentials yet to be tapped (Santrock 2007). The amount of care, affection, stimulation, interaction, education and training received by children in early years have tremendous impact on holistic development, general wellbeing and success throughout life. This clarifies the amount of impetus given to stimulation in the early education which will tap and match each individual child's developmental stage and learning style, so that each child is given the best preparation for starting and completing school successfully.

Virtually, the practice of early childhood education is based on the psychological premise that the child's mind is an enchanting thing, whatever is imprinted in it remains inedible and has long lasting effect even in adulthood, but empirical findings reveal short term, long term and fade out of gains obtain in preschool. This has generated arguments, continuous researches and tentative results.

\section{Persistence Influence of Nursery Education and on Cognitive and Psycho-Social Competence of Participants at Primary School Levels.}

Studies were conducted to find durations of preschool gains and to unravel the issue of fade-out or marginalisation of the gains in subsequent educational stages. The research conducted by Mills, Dale, Cole, Jenkins and Joseph, (1995) through a follow-up of children from academic and cognitive preschool curricula to age 9 shows that the starting level of development and achievements of children predetermines their whole career at school and their social interaction. Similarly Morcan (1999) conducted a follow-up study of children who started school at age 4 (referred to as Year 1 in the study) to examine the influence of three different preschool models on later school success. The study examined report card grades, retention rates, and special education placement of 160 children at the end of their fifth year in school and 183 children at the end of their sixth year in school. The result shows evidence of quality preschool years on achievement and success in later schooling. This means preschool influence on achievement was not wipe-out in subsequent or later stages of leaming.

The EPPE (1990-2000) reports on the primary school phase of the research, focused on the end of primary school (Years 5 and 6 when children were aged 10/11 years old). The results clearly demonstiate the importance of investment in early years, especially for children from disadvantaged backgrounds and for those who go on to 
primary education of poorer quality. Keytaz (2004) discovered that the nursery school increases academic performance through engaged reading. He found that nursery school served as intervention for physical, social and intellectual growth of children in their early years. He added that children who had quality preschool education tend to be more successful in later school, and are more competent socially, emotionally, and are more academically directed. This means that children's later school success appears to have been enhanced by more active, child-initiated early learning experiences. But Westein (2004) indicated that the long term progress attained in nursery school may be slowed down by formalized over didactic academic school experiments which are introduced too early for children. These, they said could backfire when the children move into higher elementary school. The inference here is that those who scored low were attributed to be slowed by overly academic preschool experiences, and early introduction of formalized learning experiences, or high academic activities that were too early for most children's developmental status.

Lee and Loeb (2009) reported that the effects were found to diminish toward the end of elementary schools. Snell (2008) and Karen (2009) revealed that the effect of nursery school on cognitive competence does not last long, Similarly, studies conducted by Sammon, Sylva, Melhuish, Saraj, Taggart, and Hunt (2008), on year 5 children, discovered that at the end of 6 years schooling, there are no longer statistically significant net effects for type of preschool attended, duration in attending Pre School or age of starting Pre-school on all out comes. This supported the contention that the Pre School benefits gained fade out after some time. This shows that the positive effects are short lived or may diminish or disappear with time as children progress into higher classes. This implies that achievement differences measurable as a result of preschool education diminishes over time and are not significant after some years of further instruction as marginalisation occurs.

However, the Perry Preschool Study Follow-up data (1990-2000) revealed mixed results. Eight out of nine longitudinal studies reported a demonstrated superior literacy achievement at ages 10,14, and 19 over control-group participants who did not attend the preschool. While only one reported that the cognitive advantage gained by children who attended preschool did not endure past the first few years in elementary school. These results show diverse ways in which preschool education demonstrated positive, short and long-lasting benefits and fade out effects linked to cognitive dimensions of school achievement.

The studies cited were neither unanimous nor conclusive in their findings; this raises the need to undertake more researches to unravel the influence of nursery school education on participants as they proceed on their education, especially when compared with non participants. The uniqueness and gap to be filled by the current study is to establish the continuous influence of newly introduced nursery education in Sokoto State public school on cognitive competence of participants in the first three years of primary school education.

\section{Research Methodology}

The survey research design was used in this study. The targeted population covered by this study was the entire primary three pupils in public primary schools in Sokoto State during the 2010/2011 academic session. The characteristics of the population are 
heterogeneous. Purposive sampling was used to choose 12 Local Governments Areas (LGAs) out of 23 LGAs, and 50 schools out of 1963. While stratified random sampling was used to choose 600 from 6,882 pupils with nursery education.

The instrument used was self designed questionnaire referred to as Cognitive Competence Questionnaire (CCQ). It was validated by the experts from Usmanu Dan-Fodiyo University, Sokoto, and primary three teachers from public nursery and primary schools. The reliability coefficient of the instrument was obtained through pilot study. The instrument was distributed to pupils and collected back immediately they finished through the assistance of class teachers and research assistants on school basis. The null- hypothesis generated by this study was tested using regression statistic.

\section{Data Presentation and Analysis}

Hypothesis 1: There is no significant relationship between performances in cognitive achievement in primary one and two and the performances in cognitive competence among primary three school children in Sokoto State.

$\mathrm{H}_{0}$ : Primary 1 Mathematics is not a better predictor of cognitive competence in Mathematics of students than Primary 2 Mathematics.

Table 1: Primary 1 Mathematics is Not a Better Predictor of Cognitive Competence of Students than Primary 2 Mathematics

\begin{tabular}{ccccccccc}
\hline Variables & $\mathrm{R}$ & $\mathrm{R}^{2}$ & $\begin{array}{c}\text { Adjusted } \\
\mathrm{R}^{2}\end{array}$ & $\mathrm{SE}$ & $\mathrm{F}$ & $\beta$ & $\mathrm{t}$ & $p$-value \\
\hline Primary 1 Math & .262 & .068 & .067 & 14.717 & 43.908 & .126 & 2.958 & .003 \\
Primary 2 Math & .373 & .139 & .136 & 14.160 & 48.212 & .298 & 6.999 & .000 \\
\hline
\end{tabular}

Dependent Variable: Cognitive Competence.

A look at the squared part correlations revealed that Primary 1 Math accounted for $2.62 \%$ of the variance in cognitive competence $R^{2}$ adj $=.067, F(1,598)=43.908, p<$ .05 . While Primary 2 Math accounted for $3.73 \%$ of the variance $R^{2}$ adj $=.136, F(2$, $597)=48.212, p<.05$. Thus, the significant results of the procedure indicated that the linear combination of the predictor variables was able to account for a significant amount of variance in the dependent variable.

Although Primary 1 Mathematics is an explanatory variable of cognitive competence, analysis of regression coefficients indicated that Primary 2 Mathematics, $\beta=.298, t=$ $6.999, p<.05$ emerged as the significant predictor when all variables were in the model. This is an indication that Primary 2 Mathematics is a better indicator of an increase in students' cognitive competence than Primary 1 Mathematics.

$\mathrm{H}_{0}$ : Primary 1 English is not a better predictor of cognitive competence in English of students than Primary 2 English. 
Table 2: $\quad$ Primary 1 English is Not a Better Predictor of Cognitive Competence in English of Students than Primary 2 English.

\begin{tabular}{lccccccccc}
\hline Variables & $\mathrm{R}$ & $\mathrm{R}^{2}$ & $\begin{array}{c}\text { Adjusted } \\
\mathrm{R}^{2}\end{array}$ & $\mathrm{SE}$ & $\mathrm{F}$ & $\beta$ & $\mathrm{t}$ & $p$-value \\
\hline Primary 1 English & .158 & .025 & .023 & 14.766 & 15.249 & .132 & 3.183 & .002 \\
Primary 2 English & .190 & .036 & .033 & 14.694 & 11.146 & .109 & 2.626 & .009 \\
\hline
\end{tabular}

Dependent Variable: Cognitive Competence.

A look at the squared part correlations in Table 2 revealed that Primary 1 English accounted for $1.58 \%$ of the variance in cognitive competence $R^{2}$ adj $=.023, F(1,598)$ $=15.249, p<.05$. While Primary 2 English accounted for $1.90 \%$ of the variance $R^{2}$ $a d j=.033, F(2,597)=11.146, p<.05$. Thus, the significant results of the procedure indicated that the linear combination of the predictor variables was able to account for a significant amount of variance in the dependent variable.

Although Primary 2 English is an explanatory variable of cognitive competence, analysis of regression coefficients indicated that Primary 1 English, $\beta=.132, t=$ $3.183, p<.05$ emerged as the significant predictor when all variables were in the model. This is an indication that Primary 1 English is a better indicator of an increase in students' cognitive competence than Primary 2 English.

$\mathrm{H}_{0}$ : Primary 1 General Knowledge is not a better predictor of cognitive competence in General Knowledge of students than Primary 2 General Knowledge.

Table 3: Primary 1 General Knowledge is Not a Better Predictor of Cognitive Competence in General Knowledge of Students Than Primary 2 General Knowledge.

\begin{tabular}{ccccccccc}
\hline Variables & $\mathrm{R}$ & $\mathrm{R}^{2}$ & $\begin{array}{c}\text { Adjusted } \\
\mathrm{R}^{2}\end{array}$ & $\mathrm{SE}$ & $\mathrm{F}$ & $\beta$ & $\mathrm{t}$ & $p$-value \\
\hline Primary 1 GK & .199 & .040 & .038 & 13.914 & 24.598 & .149 & 3.266 & .001 \\
Primary 2 GK & .218 & .048 & .044 & 13.868 & 14.898 & .103 & 2.243 & .025 \\
\hline
\end{tabular}

Dependent Variable: Cognitive Competence.

A look at the squared part correlations revealed that Primary 1 General Knowledge accounted for $1.99 \%$ of the variance in cognitive competence $R^{2}$ adj $=.038, F(1,598)$ $=24.598, p<.05$. While Primary 2 General Knowledge accounted for $2.18 \%$ of the variance $R^{2}$ adj $=.044, F(2,597)=14.898, p<.05$. Thus, the significant results of the procedure indicated that the linear combination of the predictor variables was able to account for a significant amount of variance in the dependent variable.

Although Primary 2 General Knowledge is an explanatory variable of cognitive competence, analysis of regression coefficients indicated that Primary 1 General Knowledge, $\beta=.149, t=3.266, p<.05$ emerged as the significant predictor when all variables were in the model. This is an indication that Primary 1 General Knowledge 
is a better indicator of an increase in students' cognitive competence than Primary 2 General Knowledge.

\section{Discussion of the Research Findings}

Hypothesis one seek to compare previous performances of pupils in Primary One and Two with their performances in cognitive competence test used in this study at primary three. The cognitive achievement score on Mathematics, English and General Knowledge were obtained from their end of year result sheets in primary one and two. This study assessed the consistency in the influence of nursery education on performances of pupils as they proceed in schooling. In this regard primary one and two scores were compared and correlated with the results obtained in cognitive competence test in primary three. The calculated values obtained showed some coherence at significant level of $\mathrm{p}<.05$. The null hypothesis was rejected. This implies that the academic gains of nursery education have been sustained by the pupils at primary three. This finding corresponds with Turkey by Morcan (1999), Keytaz (2004) and EPPE (1990-2000). This implies that children who had nursery education tend to be more successful in later schooling,

But the findings of the present study did not concur with Westein (2009), and that the long term progress attained in nursery school may be slowed down by formalized over didactic academic school experiments which are introduced too early for children. These, they said, could backfire when the children move into higher elementary school. It also contradicted the finding of Lee and Loeb (2009) on fade out of acquired gains. This means that exposing children at very early age and to core or pure academic programmes as practiced in the nursery school setting in Sokoto State did not fade nor marginalised. Rather, this study revealed that there is significant correlation between their primary one and two results with that of cognitive competence scores obtained in English, Math and General Knowledge in primary three. So, the issue of fading has not been established by this study.

The present study also observed that the pupils who attended nursery education were able to maintain higher scores in both previous achievement record in primary one and two and their performances in CCQ at primary three than their counterparts. This means that there is corresponding influence of nursery education on academic competences of primary school pupils in Sokoto State as they performed better than those who had no nursery education through-out the initial three years of primary education, but the problem identified was that their general academic capacity was below the required standard provided for in the national syllabus for primary three. In other words, though those with nursery education actually performed better in both classroom achievement test (school exams) and in CCQ but their performance rate was low which might have resulted in the current falling standard of education across the educational institutions. This is attributed poor quality and inadequacies in human and material resources in teaching and learning which are necessary for quality educational outcomes. The implication is that despite this default participants were able to surpass non participants. It means that if they were exposed to better quality teaching and facilities they would have also performed correspondingly better and their academic capacity will be higher and will rise to desire standard. 


\section{Summary of Findings}

1. There is significant correlation between cognitive achievement in primary one and two and performance in Math, English and General Knowledge aspects of cognitive competence in primary three.

\section{Conclusion}

The findings of present study reveal significant influence of nursery on cognitive competence during the duration of first three years of primary school. This implies that preschool benefits on performance were sustained in the initial years of learning. The long term effect can only be substantiated by follow-up or longitudinal research. This is actually beyond the scope of present study and desired for further research.

\section{Recommendations}

1. To address problem of low cognitive capacity and enhance standard, there should be proper monitoring and supervision to ensure quality, standard, linkage in educational delivery at preschool and primary school. This means that both preschool and primary school must be of comparable standard and quality, otherwise problem of incompatibility might cause some problems, such as the fade-out, wash out or diminishing of the earlier gains.

2. The UBE scheme providers should ensure that examinations and evaluation of learning outcomes include assessment of pupils on psycho-social and motor domains along with the academic domain of development and be contained in examination report card issued to learners at the end of term, or annually at the end of year and even on certificates issued at the completion of each school programme. This will certify that learners possess credibility in learning and character.

\section{References}

Balinski, T. M. (2008). UNICEF; Daycare is "A high-stakes gamble with Today" Children http: $1 /$ www.lifesitenews.com/idn/2008.dec/08/2/603:html.

Retrieved 30- 19-2009.

Barnnet, S. (1953). Benefits of Compensatory Preschool Education. Journal of Human Resources. 279-312.

Barnett, W.S. (1995; 2007). Long-Term Effects of Early Childhood Programs on Cognitive and School Outcome. The Future of Children, 5 (3): 25-50.

EFA (2000). World Education Forum Assessment; Statistical Documents, Executive Summary. Dakar Senegal 26-28 April,2000. http.//www.74.125.47.132/search?q=kozBOHpsWol:unesco.org/images100. Retrieved 01/10/2009.

EPPE Reports (1990). The Effective Provision Of Pre-School Education Project (1990-2000), London: DFES And Institute Of Education, University Of London.

Essa, E.L. (1999). Introduction to Early Childhood Education. Bostin. Delmar publishers.

Karen, (2009). The Case Against Government Preschool-Myth vs. Facts http://74.125.95.132/search?q=cache:6PTh3gzawxUJ:www.edwatch.org/pdfs/0331 09 Retrieved 30-09 2009 
Katz, L.G., \& McClellan, D.Z. (1997). Fostering Children Social Competence; The Teacher's Role. Washington. D.C. National Association for the Young Children

Kaytaz M. (2004). A Cost Benefit Analysis of Preschool Education in Turkey. Bo Azici University.

Lee, V, E., \& Loeb, S. (2009). Where Do Head Start Attendees End? Reasons Why

http:/www.eric.ed.gov/ERICDọcs/data/ericdocs2sql/content storage 01/0000019b/8015/6e/f7. pdf Retrieved 10/10/2009.

Lee, E., Brook-Gunn, J., Schnur, E., \& Liaw, F. R. (1990). Are Head Start Effects Sustained? A Longitudinal Follow-up Comparison of Disadvantaged Children Attending Head Start, No Preschool and Other Preschool Programmes. Child Development .61(2): 495-507

Morcan, R..A., (1999). Moving Up The Grades: Relationship Between Preschool Model and Later School Success. Early Childhood Research Quarterly. University of North Florida

Mills, P. E.; Dale, P. S.; Cole, K. N.; \& Jenkins, J. R.. (1995). Follow-Up Of Children From Academic And Cognitive Preschool Curricula at Age 9. Exceptional Children, 61 (4): 378-393. EJ 497634

Santrock, J. W. (2007). Children (9th edition) Boston, McGraw-Hill Higher Education.

Sammons, P., Sylva K,. Melhuish, E., Saraj Blatchford, I., Taggart B., \& Hunt, S. (2008). EPPE: Influences on Children's Attainment and Progress in Key Stage 2: Cognitive Outcomes in Year 6. http.//www.dcsf.gov.uk/research/data/uploadfiles/dccf-RR048.Retrieved Sept 14 2010

Snell, L. (2008). More Education That Universal Preschool Doesn't Offer Lasting Benefits. http://Reason.org/news.show/1003109.html. Retrieved. 01-10/2009 